\title{
INFLUJOS CERVANTINOS EN EL PICKWICH DE DICKENS
}

Es bien sabido que Cervantes, supremo renovador de la literatura hispana y genial creador de Don Quijote, influyó poderosamente en la literatura europea. Su impacto sobre la novela inglesa fue decisivo. Numerosas traducciones en inglés, reediciones, versiones abreviadas y adaptaciones en forma de novelas, poemas y obras teatrales, atestiguan la inmensa popularidad de Don Quijote en Inglaterra desde que se tradujo en este país por primera vez en 1612 (sólo siete años después de su aparición en España).

Existen múltiples novelas, inspiradas en cierto modo en la de Cervantes, cuyos protagonistas, llamados "héroes quijotescos", presentan características comunes: amor a la justicia, fortaleza para sufrir penalidades o burlas, aspecto usualmente estrafalario, indiferencia en competiciones de tipo sexual; y, usualmente, edad superior a la de los héroes ordinarios. Además, persiguen ideales ilusorios que nosotros admiramos, incluso si los consideramos ridículos, por lo que nos inspiran amor y respeto aunque susciten nuestra risa.

Según Welsh ${ }^{1}$ los autores que mejor han captado la esencia de Don Quijote son Fielding, Sterne, Dickens y Dostoievski, en cuyas respectivas obras Joseph Andrews, Tristam Shandy, Pickwick y El Idiota, figuran héroes quijotescos. En El Vicario de Wakefield, de Goldsmith, el protagonista es copia del cura Adams, el Quijote a la inglesa de Joseph Andrews de Fielding; y el héroe de Scott

\footnotetext{
1 Alexander Welsh (1981), PP. 3-16.
} 
en Waverley es una versión de un don Quijote rejuvenecido ${ }^{2}$. La lista podría alargarse.

Las novelas quijotescas inglesas no confiesan su génesis cervantina tan abiertamente como se hace en Joseph Andrews, a la que su autor, Fielding, agregó este subtítulo (que hoy en día suele omitirse ${ }^{3}$ ): Written in Imitation of the Manner of Cervantes, Author of Don Quixote. En cambio, Dostoievski, cuyo Príncipe Mischkin, héroe de El Idiota, está también inspirado en Cervantes, explica en una carta ${ }^{4}$ : He tratado de retratar a un hombre realmente noble, con referencia a Cristo, Don Quijote y Mr. Pickwick»; y anade que uen el Pickwick de Dickens no se alude a Cervantes, a pesar de ser la única novela quijotesca de talla, en cualquier lenguaje, que incluye una plena reencarnación de Sancho Panza». Otros escritores han comentado también el parentesco entre Don Quijote y Pickwick: Taine, Turgueniev, Washington Irving y Ramón Pérez de Ayala ${ }^{5}$, entre otros muchos.

La filiación cervantina del Pickwick está, pues, plenamente admitida. Los ingleses la notaron enseguida ${ }^{\circ}$; y cuando apareció Sam Weller, el criado de Mr. Pickwick, en la cuarta de las entregas mensuales, los críticos lo celebraron como a un Sancho Panza dickensiano. Sin embargo, los comentaristas ingleses hablan cada vez menos de la conexión entre The Pickwick Papers y Don Quijote. Así, Forster ${ }^{7}$, amigo íntimo y primer biógrafo de Dickens, escribe en 1872: "Sam Weller y Mr. Pickwick son el Sancho Panza y don Quijote londinenses... Carecemos de medios para decidir si Dickens era consciente de su deuda para con Cervantes, por, lo mismo que David Copperfield, había leído Don Quijote cuando niño". Johnson ${ }^{8}$, el segundo gran biógrafo de Dickens, comenta en 1952 el parentesco entre los dos protagonistas sin referirse al de los criados. En una extensa biografía ${ }^{9}$ de Dickens publicada en 1990 no se habla en absoluto de una

2 Alexander Welsh (1981), p. 149.

3 Walter Allen (1954), p. 56.

4 Alexander Welsh (1981), p. 150.

5 Pérez de Ayala (1958) (cap. "Cervantes en Dickens», p. 63).

- Un crítico dijo en el Metropolitan Magazine (enero 1837): "El renombrado Mr. Pickwick es el legítimo sucesor de Don Quijote; un Quijote londinense del siglo xIX que, en vez de armadura de hierro, viste pomposa levita, y en lugar de lanza se vale de su oratoria para entablar batalla contra el tramposo, el malhechor y el opresor del inocenten.

7 JOHN FORSTER (1980).

E. JohNSON (1977).

9 Peter Ackroyd (1990). Una voluminosa biografía, de 1200 pp., 200 de ellas dedicadas al Pickwick. El autor afirma que nada se sabe sobre los origenes de esta obra. 
relación entre las dos obras. En fin, Chesterton ${ }^{10}$, considerado como el más fino de los críticos de Dickens, no menciona una conexión entre don Quijote y Mr. Pickwick, a pesar de valorar a este último como a un tipo universal de la humanidad.

No existen trabajos dedicados exclusivamente al tema de la afinidad entre el Pickwick y Don Quijote, afinidad que, por otra parte, no se limita a la simple analogía entre las dos parejas amocriado sino que, como veremos, va bastante más lejos. Un atento cotejo de los dos textos permite detectar muchos puntos de semejanza entre las novelas. El objeto del presente ensayo es poner de manifiesto conexiones entre caracteres, tema, argumento, tópicos, estructura y estilo de las dos obras, describiendo los principales paralelos que las relacionan.

Varias razones pueden ayudarnos a explicar que el Pickwick y Don Quijote presenten la sorprendente similitud que sugiere nuestro ensayo: Entre ellas, la gran admiración de Dickens por Don Quijote y, quizá también, por el portentoso éxito que había tenido la obra; el profundo conocimiento que tenía de ella, por haberla leído ávidamente desde niño; el efecto indirecto de Cervantes sobre el novelista, a través de autores ingleses, influidos incuestionablemente por el autor español (Fielding, Smollett, Sterne, Goldsmith, Scott) con cuyas novelas Dickens estaba familiarizado, también desde temprana edad. Además, con sólo 24 años, pasaba por circunstancias excepcionales: Haciendo con gran tesón reportajes parlamentarios, componía una opereta, y se dedicaba a otras tareas menores. A punto de casarse, estaba cambiando de domicilio. En fin, ante la oferta de tentadores emolumentos, se había comprometido a escribir su Pickwick entregando manuscritos de extensión tasada, y a plazos fijos apremiantes. Se ha escrito " que "Pickwick fue la única novela de Dickens compuesta atendiendo una demanda externa... con un plan rudimentario que le fue sugerido por tres o cuatro personasn. Y, casualmente, este esbozo de plan era afín al de Don Quijote. Ante estos hechos, no parece ilógico, ni detrimental para el mérito de Dickens, que ideas de Cervantes, genialmente incorporadas a su jugosa prosa, destilasen hacia una primera novela que, además, se escribía a marchas forzadas ${ }^{12}$. Es oportuno recordar que las

${ }^{10}$ G. K. Chesterton (1906) y (1911).

"John Butt y Kathleen Tillorson (1957), p. 58.

12 Escribiendo a su novia a mediados de marzo (1836), Dickens confiesa que está «exhausto en cuerpo y almaw; pero a finales de mes ha terminado ya los dos primeros números del Pickwick (24.000 palabras). Cobra sus 29 libras, se casa, y disfruta de su luna de miel. (El primer número del Pickwick aparece ya a principios de abril). 
primeras palabras que Dickens escribió en su Oliver Twist ( «En una ciudad que por muchas razones es prudente no citar") parodian las que dan principio a Don Quijote ( $«$ En un lugar de la Mancha, de cuyo nombre no quiero acordarme"). Teniendo en cuenta que Pickwick y Oliver Twist se escribieron casi a la vez ${ }^{13}$, resulta evidente que el novelista inglés conocía muy bien la obra de Cervantes, y que no trataba de ocultarlo.

El paralelismo más ostensible (puede decirse que el único sobre el cual se ha escrito algo), se refiere a las dos parejas amocriado. La edad de Mr. Pickwick (un hombre de negocios retirado) se asemeja a la de don Quijote que "frisaba en los cincuenta años». En su aspecto externo, los dos personajes se salen de lo común: Don Quijote es alto y delgado, casi cadavérico, parco en el comer y el beber; Mr. Pickwick es más bien bajo, obeso ${ }^{14}$, rubicundo, aficionado al ponche y a la buena mesa. El atuendo inusitado del primero, con celada, adarga y lanza, que, junto con su estrafalaria figura, le confiere un aspecto grotesco, presenta cierta correlación con el bizarro porte del calvo y barrigudo $\mathrm{Mr}$. Pickwick, que luce levita de largos faldones, pantalones ajustados y polainas (prendas poco corrientes que la novela ridiculiza en varias ocasiones). Ambos personajes, elocuentes, caballerosos e inocentes, se ganan muy pronto nuestro afecto. Si bien algo propensos a la cólera, se sosiegan con facilidad. Los dos nos parecen solteros incontrovertibles, dotados de un espíritu joven: gustan de las aventuras y son capaces de realizar proezas que sentarían mejor a hombres más jóvenes ${ }^{15}$. Al principio, $\mathrm{Mr}$. Pickwick se manifiesta como un pomposo fatuo o un amable bufon, y don Quijote exhibe una mezcla de locura visionaria e inteligente lucidez; mas, a medida que las narraciones avanzan, los dos protagonistas ganan en dignidad, en especial al final de las novelas.

Sam Weller y Sancho Panza difieren radicalmente de sus respectivos amos en su constitución física: Sam es más bien alto y delgado; Sancho, bajo y rechoncho. Notamos en las dos parejas amo-criado una especie de simetría invertida en cuanto a las

${ }^{13}$ Oliver Twist se publicó también por entregas mensuales. La primera de ellas coincidió con la del número nueve del Pickwick que ocupó veinte números, en total.

14 Inicialmente, se había dibujado un Mr. Pickwick delgado; pero el editor Chapman quiso que Dickens lo representase obeso.

15 Por ejemplo, en Sierra Morena, don Quijote da «dos zapatetas en el aire y dos tumbos la cabeza abajo y los pies en el alto* (final cap. 25, parte I). En Manor Farm, Mr. Pickwick deja admirados a los presentes al deslizar por un resbaladero practicado en el hielo *con un ardor y entusiasmo que nada habría podido aminorar» (mitad del cap. 30). 
complexiones. (Veremos ocasionalmente otros casos de inversión.) Sam posee el espíritu del cockney londinense de los barrios bajos; Sancho es un rústico típico. Y ambos dan muestras de la práctica agudez que confiere la experiencia, con una mezcla de simplicidad y cazurrería, junto con su poquito de amoralidad y de cinismo. Fielmente devotos a sus amos, los respetan y admiran, aunque en ciertas situaciones funcionan como sus protectores. Sus familiares tienen particular relieve: la mujer y la hija de Sancho; el padre de Sam Weller y su esposa Mrs. Weller, madrastra de Sam. En las suculentas cartas con que los dos autores divierten al lector (otra semejanza), se saca gran partido de estos allegados, con cómicas misivas escritas o recibidas por ellos o por los protagonistas (cap. 15, parte I, y caps. 36, 51 y 52, parte II, del Quijote; y caps. 3 y 52 del Pickwick). A veces, los sirvientes despliegan una capacidad de recursos que deja sorprendidos a todos los presentes: por ejemplo, Sancho, en el gobierno de la "ínsula»; Sam, en la "soirée» de criados de buena casa (cap. 37), en donde, aunque un novato, se hace amo de la situación al instante.

Es muy revelador este paralelismo: Sancho, como incansable decidor de refranes o proverbios, contenta mucho a los lectores. Y Sam Weller, haciéndose eco de Sancho, emplea repetidamente divertidos dichos, en forma de símiles más o menos sofisticados (que los ingleses llaman "wellerismos" y los americanos "cockneyismos»). He aquí unas muestras: "Ya pasó y no tiene remedio, lo cual es un consuelo, como dicen siempre en Turquía al equivocarse y cortar la cabeza a quien no deben" (cap. 23). "Primero los negocios y después el placer, como dijo Ricardo III al apuñalar al otro rey, antes de ahogar a los chiquillos» (cap. 25). «Siento mucho causaros una molestia personal, señora, como dijo el ladrón a la vieja, al echarla al fuego" (cap. 26). (A título de curiosidad diremos que, en el cap. 50, parte I, de Don Quijote, hemos descubierto un conciso dicho de tipo welleresco que Cervantes pone en boca de Sancho, quien dice al canónigo: «...a Dios y veámonos, como dijo un ciego a otron) ${ }^{16}$.

Entre los refranes de Sancho y los dichos de Weller hay, desde

${ }^{16}$ Estos símiles no fueron inventados por Dickens. Aparecen en novelas y obras teatrales anteriores a él, y en los Sketches by Boz, del mismo Dickens (que usó este pseudónimo hasta que publicó su Pickwick). Dickens, antes de reeditar los Sketches «suprimió sus prewellerismos, lo que muestra su deseo de que estos símiles fuesen un rasgo típico de Sam» (Dickens at Work, p. 58; véase nota 11). Por lo demás, aparte del de Don Quijote, hemos descubierto en el Journal de Walter Scott varios dichos de tipo welleresco, no citados por los críticos ingleses, empleados por el propio Scott y no por personajes de fícción. 
luego, claro paralelismo. Pero, a pesar del genio de Dickens, aunque algunos wellerismos ${ }^{17}$ son espléndidos, los hay también algo rebuscados; además, resulta poco plausible que Weller pueda improvisar sus dichos con la rapidez sugerida en la novela. (Mientras los refranes son "naturales", a nuestro parecer los "afectados» wellerismos hacen de Sam una víctima de la parodia dickensiana.)

Entre los dos principales personajes femeninos, Mrs. Bardell y Dulcinea, hay afinidad. Sus papeles, poco convencionales en ambas obras, presentan un cierto parecido. Como pseudoprotagonistas, aportan continuidad a la acción, que es más bien episódica, creando un interés argumental: A través de absurdos malentendidos amatorios, los héroes son victimizados por mujeres que ellos nunca podrían o querrían desposar. Para imitar a un caballero andante auténtico, a don Quijote le conviene estar enamorado de Dulcinea. Por su parte, Mrs. Bardell, una especie de figura de Dulcinea a la inversa, se empeña en ver designios nupciales en Mr. Pickwick, porque así le place a ella. Ambas mujeres ejercen un nefasto influjo sobre el respectivo protagonista. El caballeresco enamoramiento que don Quijote piensa sentir por Dulcinea hace que su definitiva derrota a manos de Sansón Carrasco sea el acontecimiento más trágico de toda su historia, ya que le obliga a abandonar lo que él más aprecia: su condición de caballero andante. Mr. Pickwick, por no doblegarse ante los predatorios designios matrimoniales de Mrs. Bardell, sufre la más angustiosa de sus penalidades: la reclusión en la prisión de Fleet, motivada por su decisión quijotesca de negarse a pagar la indemnización y las costas que se le exigen, tras el juicio por ruptura de promesa matrimonial (caps. 34 y 40 ).

Vinculada a este episodio hay otra similaridad: Mr. Pickwick envía a Sam a Goswell Street, residencia de Mrs. Bardell (cap. 26), y Sancho, obedeciendo órdenes de don Quijote, se traslada a El Toboso, lugar de Dulcinea (cap. 25, parte I). En cada caso, el amo desea que su sirviente se las arregle para descubrir las intenciones de la dama en lo que concierne al problema amatorio que le tiene desasosegado.

En cada novela hay una segunda pareja amo-criado, antagónica de la principal. En Dickens, Alfred Jingle y Job Trotter (opuestos a Mr. Pickwick-Sam); en Cervantes, Sansón Carrasco y Tomé Cecial (en oposición con don Quijote-Sancho). En cada novela, los antagonismos desembocan en dos enfrentamientos de

${ }^{17}$ En The Dickens Encyclopaedia de Arthur Hayward (1924) figuran todos los wellerismos de los Pickwick Papers. 
resultados alternantes: En el episodio del pensionado de muchachas (cap. 16), Mr. Pickwick y Sam sucumben ante la astucia de Jingle y Job al esforzarse en salvar el honor de una colegiala. (Según una patraña que Job cuenta a Sam, Jingle se fugará con la muchacha.) Mr. Pickwick y Sam quedan en ridículo y el primero incluso sufre vilipendio. Pero en otro episodio (cap. 25), Jingle y su criado Job son desenmascarados por la pareja Mr. Pickwick-Sam y expulsados ignominiosamente de la casa de Mr. Nupkins, con cuya hija el bellaco Jingle (que se hacía llamar capitán Fitz-Marshall) trataba de casarse, lo que el héroe dickensiano y su criado logran evitar.

Por otra parte, don Quijote lucha contra Sansón Carrasco, cuyo escudero es Tomé Cecial. Sansón, que, lo mismo que Jingle, al hacerse pasar por caballero andante ha tomado otro nombre, es derrotado por don Quijote en un primer encuentro (parte II, cap. 14), pero sale vencedor en el segundo y definitivo combate (parte II, cap. 64) ${ }^{18}$. (Nótese que en el segundo enfrentamiento el derrotado es el héroe cervantino, y el vencedor el héroe de Dickens.)

Señaladas las analogías entre los personajes principales, analizaremos el paralelismo, verdaderamente notable e ignorado hasta el presente, entre los comienzos de los dos segundos capítulos. En The Pickwick Papers, al principio del segundo capítulo, leemos:

«Este siervo puntual de todo trabajo, el sol, acababa de levantarse, en la mañana del 13 de mayo de 1827 , cuando Mr. Pickwick surgió cual otro sol de su tranquilo sueño, abrió de par en par la ventana, y se asomó a contemplar el mundo exterior. A sus pies, hacia su mano derecha y su izquierda, hallábase Goswell Street... hasta donde la vista podía alcanzar... "Así", pensaba Mr. Pickwick, "son las estrechas visiones de aquellos filósofos que, contentándose con examinar las cosas que tienen ante sí, no ven las verdades que se ocultan más allá. De igual modo podría yo darme por satisfecho con mirar eternamente a Goswell Street sin esforzarme en penetrar en los ocultos parajes que por todas partes circundan esta calle", Y después de tan profunda re-

${ }_{18}$ A propósito de los cuatro sirvientes se puede notar un curioso paralelo: en cada obra los dos criados aparecen en amigable copeo. Dickens nos dice (hacia el final del cap. 45) que Sam pidió cerveza en la cantina e invitó a Trotter, el cual «se llevó el jarro a los labios y, con suave y casi imperceptible gradación, lo fue inclinando en el airex. En Don Quijote, leemos que Tomé, el escudero de Sansón Carrasco, tomó una bota de vino y la puso en manos de Sancho, el cual «la empinó, puesta en la boca, y estuvo un cuarto de hora mirando las estrellas* (final del cap. 13, parte I). Obsérvese la gran semejanza entre las expresiones entre comillas, y nótese que en los dos episodios los sirvientes de los protagonistas tienen invertidos sus papeles: el de Don Quijote (Sancho) es quien bebe, y el de Mr. Pickwick (Sam) es quien invita. 
flexión, Mr. Pickwick..., con su maletín.,., su catalejo,... y su cuaderno de notas, listo para acoger todos los descubrimientos dignos de ser registrados, llegó a la parada de coches de San Martín el Grande».

He aquí el correspondiente inicio del segundo capítulo de Don Quijote:

[Don Quijote] ...no quiso aguardar más tiempo a poner en efecto su pensamiento... Y así... una mañana antes del día (que era uno de los calurosos del mes de julio) se armó de todas sus armas, subió sobre Rocinante, puesta su mal compuesta celada, embrazó su adarga, tomó su lanza y saliendo al campo... hablaba consigo mismo diciendo: « ¿quién duda sino que... cuando salga a la luz la verdadera historia de mis famosos hechos, el sabio que los escribiere no ponga... *apenas... los pequeños y pintados pajarillos... habían saludado... la venida de la rosada Aurora que... por las puertas y balcones del manchego horizonte se mostraba, cuando el famoso caballero don Quijote de la Mancha, dejando las ociosas plumas, subió sobre Rocinante, y comenzó a caminar por el conocido campo de Montiel w... y añadió: «Dichosa edad y siglo dichoso aquel adonde saldrán a la luz las hazañas mías, dignas de entallarse con bronces... para memoria en lo futuro»

Los dos pasajes suscitan en el lector emociones estéticas similares, haciendo gala de humor y elocuencia, y empleando un lenguaje filosófico pseudo-científico, o pseudo-mitológico, de acuerdo con sus personajes, los autores hacen burla afectuosa de sus héroes. Además, coinciden al seleccionar los hechos esenciales narrados. Nos hablan del despertar de sus personajes, de cómo se visten, cómo realizan su primera salida solos, por la mañana muy temprano, en época calurosa. Los vemos sin un servidor, y sin pensar en la eventualidad de tomar uno. Mr. Pickwick «surge cual otro sol de su tranquilo sueñon, mientras don Quijote "deja las ociosas plumas cuando la rosada Aurora acaba de mostrarse por el manchego horizonten, lo que equivale a decir que don Quijote, lo mismo que Mr. Pickwick, «surge de su sueño cual otro sol». (Un sol mitológico en Cervantes y «un sol puntual de todo trabajon en Dickens). Los lectores se enteran de que $\mathrm{Mr}$. Pickwick se equipa con su maletín, su catalejo y su cuaderno de notas, en tanto que don Quijote se provee de celada, adarga y lanza. Los autores ceden al mismo impulso, al revelarnos los exaltados pensamientos de sus personajes, en los que la pedante filosofía de Mr. Pickwick hace juego con los desatinos caballerescos de don Quijote. Es singular esta coincidencia: mientras el exnegociante Mr. Pickwick piensa en descubrimientos dignos de ser anotados en un cuaderno, don Quijote, menos prosaico, imagina hazañas dignas de ser entalladas en bronces. 
He aquí otra conexión entre los protagonistas de la primera salida: ambos la inician sirviéndose de un caballo. Don Quijote sube sobre Rocinante, un rocín «todo piel y huesos». Mr. Pickwick, un Quijote del siglo XIX, monta en un coche del que tira un jamelgo (objeto de humorísticos comentarios en el mismo cap. 2) aquejado de una flojera más deplorable aún que la de Rocinante ${ }^{19}$. (Notemos de paso que, al final de su trayecto, $\mathrm{Mr}$. Pickwick recibe puñetazos y golpes, agresiones que casan bien con las que sufre don Quijote, ya en la primera de sus aventuras.)

Otra curiosa semejanza: los criados surgen en momentos análogos de las dos narraciones. Los héroes realizan su primera salida desprovistos de sirviente, protagonizan aventuras y peripecias, y retornan a sus casas. $\mathrm{Y}$ justo antes de emprender su segunda salida, coinciden en contratar a sus criados, Sam y Sancho, curiosamente de nombres algo parecidos (Quijote, parte I, cap. 7; Pickwick, cap. 13). Es bien sabido que Sancho Panza contribuyó enormemente al éxito de Don Quijote, deleitando a toda clase de lectores. Y desde que Dickens, en su cuarto número, introdujo en su Pickwick al criado Sam Weller, las ventas de la obra (hasta entonces muy modestas) crecieron de manera exorbitante. Sam contribuyó mucho a que Dickens, catapultado hacia la fama, se convirtiese en la primera figura literaria de la Inglaterra de su época.

Sancho y Sam no sólo permanecieron leal e indisolublemente unidos a sus amos mientras éstos vivieron, sino que proporcionan el paralelismo más conspicuo e ininterrumpido que conecta las obras: una multifacética similitud, con ingredientes de patronazgo y paternidad por parte de los amos, y de respeto y devoción casi filial -siempre compatible con un comportamiento nada servil- por parte de los criados.

Hay algún episodio del Pickwick que recuerda de modo especial otro del Quijote. Por ejemplo, se observa una clara semejanza entre la «Antiquarian Discovery» (cap. 11) y la «Ganancia del yelmo de Mambrino» (parte I, cap. 21). El visionario don Quijote confunde con el famoso yelmo de oro la relumbrante bacía de azófar, recién estrenada, con la que un barbero se protege contra la lluvia. Al instante, nuestro héroe se apodera de la bacía

${ }^{19}$ Los autores hacen gran hincapié en la comicidad de sus personajes y su caballo. Cervantes nos narra, por ejemplo, los apuros que las amorosas indiscreciones de Rocinante causaron a don Quijote (parte I, cap. 15). En Dickens, encontramos una aventura ecuestre, rebosante de humor (cap. 5). Vease también el artículo *Waverley, Pickwick and Don Quixote» en Nineteenth Century Fiction, de Alexander Welsh (1967). 
por la fuerza, orgulloso de la posesión del "yelmo que tanto había deseadon. La naturaleza del baci-yelmo es objeto de discusiones largas, cómicas, e incluso tediosas para el lector. Mas, a pesar de las protestas del barbero, y contra toda evidencia, whasta el día del juicio... la bacía se quedó por yelmo... en la imaginación de don Quijote" (final cap. 45).

Mr. Pickwick, a su vez, al ver en el umbral de una casa una losa grabada con la inscripción «BILST UM PSHI S.M. ARK» la compra sin pensarlo dos veces, convencido de haber hecho realidad "uno de los máximos objetivos de su ambición»: efectuar un notable descubrimiento. El significado de la inscripción motiva vastas especulaciones, crea rencillas y envidias; y sociedades arqueológicas interesadas en el asunto nada sacan en limpio sobre el asunto. Sin embargo, el iletrado vendedor de la losa, asegura haberlas grabado él mismo, con la intención de escribir: «BILL STUMPS, HIS MARK» ( «BILL STUMPS, SU FIRMA», o sea, «firma de Guillermo Stumps»). Pero a Mr. Pickwick nada le apea de su credulidad, pues Dickens nos dice que "hasta nuestros días, la losa sigue siendo un ilegible monumento a la grandeza de $\mathrm{Mr}$. Pickwick» ${ }^{20}$. La semejanza entre los dos episodios es obvia: Los ridículos «descubrimientos» de un terco aprendiz de arqueólogo remedan las insensateces de un iluso caballero andante.

Chesterton ${ }^{21}$ comenta ucuán bien le cuadra a Mr. Pickwick el rescatar damas en peligro y desafiar tiranos». El acierto de este comentario se confirma en el ya citado episodio del pensionado de muchachas (cap. 16) donde el pícaro Job engaña a Sam fingiendo que Jingle intenta fugarse con una colegiala. La credulidad de Mr. Pickwick, y los resultados de su absurda intervención para evitar la imaginaria huida, nos recuerdan empeños pa-

${ }^{20}$ Es muy posible que Dickens tomase «prestada su losa de un episodio de The Antiquary, de Scott (cap. 4), cuyo protagonista, Oldbuck, un anticuario apasionado, algo marrullero, atribuye a una inscripción grabada en una piedra un significado histórico obviamente falso. Por lo demás, es muy probable que Scott (gran admirador de Cervantes, a quien cita con frecuencia en sus novelas) se inspirase en Don Quijote para escribir su episodio, ya que, poco antes de narrarlo, comenta que don Quijote habla vendido hanegas de tierra de sembradura para comprar libros de caballerías (casi lo mismo que hizo Oldbuck, pues trocó buenas tierras por los campos estériles que contenían la piedra grabada que, en un principio, él creyó genuina). Pero es casi seguro que Dickens, en su "Antiquarian Discovery», se inspiró directamente en el "Yelmo de mambrino», ya que en estas dos aventuras los objetos en litigio son descubiertos de modo súbito, tomados en el acto y transportados a otros lugares. Su naturaleza es largamente discutida, pero cada posesor rechaza la interpretación lógica y se aferra a la errónea. Nada de esto sucede en el episodio de Scott, en el cual Oldbuck sabe bien que está equivocado y soborna a un inferior para comprar su silencio.

${ }^{21}$ G. K. Chesterton (1906), p. 68. 
recidos en los que don Quijote trata de enderezar entuertos o deshacer agravios. Por ejemplo, la liberación de los galeotes (parte I, cap. 22), o la defensa del muchacho azotado por su amo (parte I, cap. 4). Mr. Pickwick, tras la aventura del pensionado, aparte del ridículo, la vejación y el vilipendio (las profesoras insinúan que es un viejo verde), sufre un ataque de reumatismo que le tiene en cama varios días (cap. 17). Por su parte, don Quijote es apedreado por Ginés y sus compañeros después de libertar a los galeotes, y ridiculizado por el muchacho, que hace burla de una intromisión que sólo ha servido para que su cruel amo le propine azotes suplementarios.

Encontramos otros incidentes paralelos que ponen de especial relieve el comportamiento altamente caballeresco de los protagonistas. Por ejemplo, don Quijote que, en honor de Dulcinea, hacía penitencia voluntaria en Sierra Morena, a petición de sus amigos, renuncia a la misma para ponerse en condiciones de proteger a la princesa Micomicona contra el gigante que la acosa (parte I, cap. 29). Por su parte, Mr. Pickwick, acepta voluntariamente los rigores de la prisión antes que ceder a las extorsiones de los abogados (caps. 34 y 40 ) cuando el juicio por rotura de promesa matrimonial se decide en su contra. Pero, ante los ruegos de sus amigos, accede caballerescamente a pagar las costas del juicio (cap. 47), queda libre, y puede así proteger a dos enamorados en desgracia: Mr. Winkle y Arabella. Además, devolviendo bien por mal, libera de paso a su compañera de prisión, Mrs. Bardell, encarcelada porque los abogados le reclamaban las costas que Mr. Pickwick, como paladín de la Justicia, no quiso pagar al acabar el juicio (cap. 34).

Hay otros ejemplos de paralelismo, de variada índole, cuatro de los cuales se citan brevemente a continuación:

Aunque hombres castos, ambos protagonistas se ven involucrados en una aventura de "confusión de lechos", en donde el personaje femenino tiene un novio celoso y vengativo (Quijote, parte I, cap. 26; Pickwick, cap. 22). (Se puede objetar que el paralelismo es poco significativo, ya que tales aventuras son muy comunes, pero la honestidad de los personajes masculinos les confiere una semejanza especial.)

Ambos héroes disfrutan, precisamente en dos ocasiones, de una munificente hospitalidad. Don Quijote en el castillo del duque, y Mr. Pickwick en Manor Farm (caps. 6 y 28), la finca de su amigo Mr. Wardle, en Dingley Dell.

En ambas obras vemos a nuestros hombres, profundamente dormidos, transportados en vehículos de ruedas, ante la hilaridad de los presentes. Se pretende someterles a una cura de 
desintoxicación: obsesión caballeresca en don Quijote (parte I, cap. 45); exceso de ponche en Mr. Pickwick (cap. 19).

Repetidamente, los héroes son objeto de atenciones, arrumacos y cariñosos mimos por parte de personajes femeninos: Don Quijote se imagina servido por ilustres damas (parte I, cap. 2). Hermosas doncellas lo cubren con «un gran manto de finísima escarlata” (parte II, cap. 33). Es rociado con aguas perfumadas y agasajado por la duquesa y sus mujeres. Cree ser adorado por la bella Altisidora, etc. Por otra parte, en Navidad, lindas muchachas besan a Mr. Pickwick debajo de la rama de muérdago en Manor Farm (cap. 28). Diversas damas lo galantean en variados episodios de la novela: Mrs. Pott (cap. 13), Mrs. Leo Hunter (cap. 15), y la propia Mrs. Bardell. Incluso una anciana dama invita a Mr. Pickwick "con una dulzura irresistible» a que tome el té con ella (cap. 48).

El final de las novelas es parecido: ambas terminan cuando acaban las aventuras del protagonista. En Dickens, se disuelve el Club presidido por Mr. Pickwick, éste renuncia a sus salidas, se instala como sosegado gentleman, y recibe asiduas visitas de los amigos que han compartido sus aventuras (Winkle, Tupman, Snodgrass). Como siempre, le atiende su criado Sam, decidido a sacrificar sus inclinaciones amorosas sometiéndose a un celibato indefinido. El héroe cervantino, habiendo sido derrotado por Sansón Carrasco, ha de abandonar sus aventuras obligado por una promesa previa. Se retira, pues, a su casa, convertido en Alonso Quijano «con su juicio ya libre y claro", rodeado de los amigos y compañeros de muchas de sus peripecias (el cura, el barbero, el bachiller Sansón Carrasco). Su criado Sancho, lo mismo que el de Mr. Pickwick, está dispuesto a sacrificar a su amo la felicidad doméstica que tanto añoraba, acompañándole al campo, ambos con atavío de pastores, como previamente habían concertado. Mas don Quijote, enfermo de calenturas, después de confesarse y hacer testamento, muere como un cristiano hidalgo, confortado por Sancho y los demás amigos.

Puesto que en su última página Dickens declara que "Mr. Pickwick se encuentra ahora algo achacoson, y considerando que el autor cierra su obra diciendo que wentre Sam y su amo existe un afecto firme y recíproco que sólo la muerte podrá extinguir", llegamos a la conclusión de que, en lo esencial, Pickwick y Don Quijote terminan de un modo bien parecido.

Consideradas globalmente, las obras muestran características comunes. Ambas peripatéticas y trashumantes, sus rudimentarios argumentos ofrecen una innegable afinidad. (Se ha dicho de ambas que, propiamente hablando, no son realmente "novelas».) 
En una y otra un hombre maduro, claramente excéntrico, recorre su país más o menos durante un año, atendido por un fiel sirviente, y es protagonista de aventuras y peripecias de todo tipo, agradables o desafortunadas, serias o risibles. Recorre caminos, visita ventas y posadas, y se relaciona con toda clase de tipos humanos. Va dignificándose con la experiencia adquirida, y al fin se retira a su casa. Sus andanzas acaban cuando termina el libro.

Los títulos completos son algo pomposos, de estructura gramatical parecida, cada uno de siete palabras, incluyendo el nombre del protagonista:

\section{EI INGENIOSO HIDALGO DON QUIJOTE de la MANCHA The POSTHUMOUS PAPERS of the PICKWICK CLUB}

En los rótulos de los capítulos se emplea en ambas obras un lenguaje típicamente informal y humorístico. (En otras novelas provistas también de capítulos rotulados, el lenguaje que emplea Dickens en sus rótulos es simplemente descriptivo y más serio. Irónico algunas veces, casi nunca es jocoso.) $\mathrm{Si}$ el lector compara los títulos de capítulos del Pickwick y del Quijote podrá juzgar por sí mismo acerca de sus similitudes ${ }^{22}$.

Cervantes no pretende ser el verdadero padre de su Don Quijote sino sólo su padrastro, al hacer uso intermitente del escritor arábigo Cide Hamete Benengeli. Paralelamente, Dickens echa mano de un recurso parecido afirmando que su narración se ha beneficiado de las Transacciones del Club Pickwick ${ }^{23}$. Los dos autores hablan asimismo de otras fuentes más modestas (los archivos de La Mancha, el memorandum de Mr. Pickwick, etc.). (En ambos casos, las pretendidas fuentes no podrían dar cuenta de todos los hechos narrados.)

Entre las muchas novelas de Dickens, su Pickwick es la única que incluye superabundantes narraciones (casi novelitas cortas, a veces trágicas, incluso rayando en lo macabro; y también poemas) que se intercalan en el texto, y que a menudo resultan aburridas. Tales intrepretaciones no se subordinan al tema del libro, ni siquiera como episodios ilustrativos. Exactamente lo mismo ocurre en Don Quijote ${ }^{24}$.

22 Pérez de Ayal. (1958), p. 64, escribe: «Hay en Cervantes una manera típica y personal de rotular y comenzar los capítulos, que Fielding tomó para sí y que Dickens pudo tomar de Fielding».

${ }^{23}$ Walter Reed (1981), p. 28.

24 Robert L. Patten (1967), pp. 349-366. Entre otras cosas, Patten dice que «Dickens se sabía el Quijote casi de memoria y absorbió por ello las técnicas de Cervantes, junto con sus estructuras literarias». 
A pesar del intervalo de casi dos siglos que separa las obras, hay similitudes en cuanto a cualidades literarias: en ambas vemos brillantes ejemplos de prosa satírico-cómica-épica cuyo objetivo es la naturaleza humana. En las dos novelas aparecen multitud de caracteres: casi doscientos en el Pickwick y más de setecientos en Don Quijote (convictos, presidiarios, vagabundos, impostores, bribones; posaderos, criadas, clérigos, etc.). La vida de la Inglaterra Victoriana, y la de la España regida por Felipe II y Felipe III, están retratadas cual pinturas inolvidables, con elementos de picaresca y de humorístico criticismo humano y social.

Los dos libros tuvieron un éxito excepcional y sus autores adquirieron instantánea popularidad, no sólo en sus países sino también en el extranjero ${ }^{25}$. Cervantes transcendió el proposito que a menudo invoca en su novela (ridiculizar los libros de caballería) y cré la pauta de la novela moderna, interesada en la vida y costumbres comunes. Dickens, el inimitable pintor de la sociedad y maneras inglesas, abandonó también el tema que inicialmente le habían propuesto los editores (suministrar el texto para una serie de dibujos que hacían burla de malandanzas de deportistas «cockneys") y regaló al mundo la obra humorística más leída y, lo que es muy digno de destacar, escribió una novela tan diferente de todas sus demás creaciones como Don Quijote es diferente del resto de las obras cervantinas ${ }^{26}$.

Mercedes Potau

Nota adicional.-Al finalzar su Don Quijote Cervantes escribió estas palabras, laudatorias para su trabajo: «Y Cide Hamete dijo a su pluma: Aquí quedarás colgada desta espetera... a donde vivirás luengos siglos... Que... [el escritor tordesillesco] deje reposar en la sepultura los cansados y ya podridos huesos de Don Quijote... Y yo quedaré satisfecho... de haber sido el primero que goz6 el fruto de sus escritos $»$. En $1 .^{\circ}$ de nov. 1836, transcurridos sólo siete meses desde que apareciera el primer número de su Pickwick, Dickens dirigió a sus editores una eufórica carta diciendo: $\alpha \mathrm{Si}$ tuviese que vivir cien años, y escribir tres novelas en cada uno, no estaría tan satisfecho de ninguna de ellas como lo estoy de Pickwick... Espero que, mucho después que mi mano

\footnotetext{
${ }^{25}$ Muchas palabras de empleo universal han surgido de las obras: pickwickiano, wellerismo, welleresco, quijotesco, Dulcinea, Maritornes, Rocinante, etc.

${ }^{26}$ Alexander Welsh (1967), p. 20.
} 
esté tan podrida como la pluma con que la escribi, Pickwick podrá verse en muchos polvorientos estantes, acompañado de libros mucho mejores". No parece imposible que cuando Dickens (recreándose en el gran éxito de su novela) hablaba en su carta de vivir cien años, de estar satisfecho de su novela, citando su podrida mano, así como la pluma con que la escribio, se estuviese inspirando inconscientemente en el citado fragmento de Cervantes, en donde se habla de una pluma que vivirá luengos siglos, de los podridos huesos de don Quijote, y de Cide Hamete satisfecho del fruto de los escritos de la pluma.

\section{BIBLIOGRAFIA}

ACKroyd, Peter, Dickens. London, 1990.

Allen, Walter, The English Novel. London, Pelikan Books, 1954.

ButT, John and Tillotson, Kathleen, Dickens at Work. London, Methuen 1957.

Cervantes, Miguel de, Don Quixote, traducido por J. M. Cohen. London, Penguin, 1950.

Cervantes, Miguel DE, The Ingenious Gentleman Don Quixote de la Mancha. Traducción inglesa basada en la de P. A. Motteux, 2 vols. London, George Bell and Sons, 1901.

Cervantes, Miguel De, El Ingenioso hidalgo Don Quijote de la Mancha. Barcelona, Sopena, 1936.

Coluss, PHILIP, Dickens: The critical Heritage. London, Rouledge and Kegan Paul, 1971.

Chesterton, Gilbert K., Charles Dickens. London, 1906.

Chesterton, Gilbert K, Appreciations and Criticisms of the Work of Charles Dickens. London, 1911.

Dickens, Charles, The Pickwick Papers. London, Penguin, 1975.

Dickens, Charles, Papeles póstumos del Club Pickwick. Traducido por José Méndez Herrera. Obras completas, vol. 1. Madrid, Aguilar, 1960.

Forster, JoHn, The Life of Charles Dickens, 2 vols. London, Dent, 1980.

HAYWARD, ARTHUR, The Dickens Encyclopaedia. London, 1971.

Johnson, E., Charles Dickens: His Tragedy and Triumph. London, Penguin, 1977.

KARL, Fr., "The Victorian Quixote», cap. 5. A Reader's Guide to the NineteenthCentury British Novel. New York, 1975.

Patten, R. L., «The art of Pickwick's Interpolated Tales», ELH, September, 1967.

Pérez de Ayala, Ramón, «Cervantes en Dickens», Príncipios de la novela. Madrid, 1958.

Potau, Mercedes, "Notes on Parallels between. The Pickwick Papers and Don Quixote», Dickens Quarterly, vol. X, núm. 2, June, 1993.

Reed, Walter, An Exemplary History. The Quixote versus the Picaresque. The University of Chicago Press, 1981.

Rogers, P., *Mr. Pickwick's Innocence», Nineteenth Century Fiction, 1972.

SCott, Walter, The Antiquary. London, Dent, 1969.

Welsh, Alexander, Reflections on the Hero as Quixote. Princeton, Princeton University Press, 1981.

Welsh, Alexander, *Waverley, Pickwick and Don Quixoten, Nineteenth Century Fiction, June, 1967. 